\title{
Oxidative Stress in Bipolar Disorder
}

\author{
Victor Tang ${ }^{1}$ and Jun-Feng Wang ${ }^{1,2 *}$
}

${ }^{1}$ Department of Psychiatry, University of British Columbia, Vancouver, BC, Canada

${ }^{2}$ Department of Pharmacology and Therapeutics, University of Manitoba, Winnipeg, MB, Canada

\begin{abstract}
Research on the complex and multifaceted nature of Bipolar Disorder (BD) pathophysiology has recently expanded to include oxidative stress. Several lines of evidence have reported higher reactive oxygen species production that results in increased oxidative damage in proteins, lipids, and nucleic acids. These findings have been observed in brains and peripheral samples of BD patients, as well as being reproduced in a number of animal model studies. Also discussed in this review is research highlighting antioxidant properties of existing mood stabilizing drugs, with consideration paid to novel therapeutic treatments for BD through the alleviation of oxidative stress. The maladaptive oxidative modifications of cellular macromolecules may be associated with impaired neuroplasticity and the development of functional abnormalities in the brain.
\end{abstract}

Keywords: Bipolar disorder; Lipid peroxidation; Protein oxidation; Antioxidant; Mood stabilizing drugs

\section{Introduction}

Bipolar Disorder (BD) is a severe psychiatric illness characterized by cycling episodes of mania and depression. Estimates frame the prevalence of $\mathrm{BD}$ as around 1-3\% of the worldwide population. Mania is a state of excessive energy, associated with euphoria, impulsivity, lack of need for sleep, and psychosis. In contrast, depressive episodes are characterized by severely despondent and non-reactive mood, anhedonia, fatigue, psychomotor retardation, disruption of sleep and eating routines, impaired concentration, and feelings of guilt and worthlessness. BD is a leading cause of disability among individuals with medical and psychiatric conditions, and is associated with substantial morbidity and mortality. Ramifications of this chronic disease include dependence on social welfare, criminal justice intervention, and serious economic strain to patients, their families, and the healthcare system. Moreover, the healthcare burden of this disorder is exacerbated by an increased risk of other medical conditions such as cardiovascular disease, obesity, and infectious diseases.

Advances in research on $\mathrm{BD}$ neurobiology have continued to elucidate the pathophysiology, genetic predispositions, and biochemical abnormalities of this disease. Abnormal neuroplasticity has recently been recognized in $\mathrm{BD}$. Neuroplasticity is the ability to undergo and sustain change in the brain in order to maintain proper functioning. Neuroplasticity involves processes such as long-lasting modification of synapses and gene expression, neuronal growth and morphology, and the broader development of neural circuits in the brain. Dysregulation of intracellular cascades and associated gene regulation central to neuroplastic processes has been implicated in $\mathrm{BD}$ [1]. Evidence also suggests that monoaminergic, glutamatergic and neurotrophic signaling cascades are impaired [2]. Proteins involved in neuroplasticity, such as the Brain-Derived Neurotrophic Factor (BDNF) in synapse formation, differentiation, and neuronal survival, are abnormally expressed in BD [3]. Critical circuitry systems that regulate emotion, motivation, and memory are disturbed in $\mathrm{BD}$, including the Prefrontal Cortex (PFC), cingulate, hippocampus and amygdala [4]. Taken together, the dysfunction found in neuroplasticity is likely to underlie deleterious effects on cell number, density, and morphology. Indeed, research has outlined significant structural abnormalities in $\mathrm{BD}$, which may be related. Cellular abnormities are observed in postmortem brain studies showing decreased pyramidal cells in the prefrontal cortex [5], while decreased non-pyramidal cell density was found in the anterior cingulate cortex [6]. Structurally, major findings from Magnetic Resonance Imaging (MRI) studies in BD patients have shown increased ventricular size, suggesting brain tissue volume decreases, and grey matter reductions in PFC, which plays a critical role in the control and direction of mood, cognition, and motor behavior [7].

Recently, oxidative stress has been suggested to play an important role in the pathophysiology of $\mathrm{BD}$. Oxidative stress is defined as when the pro-oxidant levels in cells overwhelm the antioxidant capacity. Oxidative stress can occur through overproduction of free radicals or decrease in antioxidant defense systems or through both at once. These free radicals can cause substantial damage to macromolecules through the generation of adducts, destruction of unsaturated C-C bonds, and oxidation of disulfides [8]. More generally, they cause oxidative cell injury through damaging effects to proteins, lipids, and nucleic acids. However, when kept in controlled conditions by antioxidant systems; free radicals can serve important functions in physiological processes [9]. They are continuously produced in vivo by all tissues of the body, primarily during oxidative phosphorylation in the mitochondria. Oxygen-containing free radicals, or Reactive Oxygen Species (ROS), are typically produced as a byproduct of cellular respiration in the Electron Transport Chain (ETC). When electrons are prematurely released from complexes in the transport chain, they reduce molecular oxygen to superoxide radical, which subsequently produces various ROS through a series of biochemical cascades. A series of natural antioxidant defense systems normally eliminate ROS production and limit tissue damage: superoxide radical is dismutated by Superoxide Dismutase (SOD) to $\mathrm{H}_{2} \mathrm{O}_{2}$, which is further converted to $\mathrm{H}_{2} \mathrm{O}$ by catalase. Because the brain has only a limited amount of SOD and catalase, Glutathione (GSH) plays a key role as a major antioxidant in supporting cellular redox balance and protecting brain cells against

*Corresponding author: Jun-Feng Wang, Department of Pharmacology \& Therapeutics, University of Manitoba, 406 - 753 McDermot Ave., Winnipeg, Manitoba R3E OE3, Canada, Tel. 204-975-7705; E-mail: wangj323@cc.umanitoba.ca

Received April 16, 2012; Accepted May 17, 2012; Published May 21, 2012

Citation: Tang V, Wang JF (2012) Oxidative Stress in Bipolar Disorder. Biochem Anal Biochem S2-002. doi:10.4172/2161-1009.S2-002

Copyright: (C) 2012 Tang V, et al. This is an open-access article distributed unde the terms of the Creative Commons Attribution License, which permits unrestricted use, distribution, and reproduction in any medium, provided the original author and source are credited. 
oxidative damage by ROS. GSH is maintained by glutathione reductase that catalyzes the reduction of glutathione disulfide (GSSG) to GSH. Glutathione peroxidase (GSH-Px) catalyzes GSH reaction with $\mathrm{H}_{2} \mathrm{O}_{2}$ and converts to $\mathrm{H}_{2} \mathrm{O}$, and Glutathione S-transferase (GST) catalyzes the conjugation of oxidized products with GSH to form a non-toxic product.

Because the brain is only $2 \%$ of total body weight while metabolizing $20 \%$ of total body oxygen, it is particularly vulnerable to the production of ROS. As rising $\mathrm{O}_{2}$ concentration is associated with an increased rate of electron leakage [10], the large amount of oxygen consumed by the brain may result in high superoxide formation. Furthermore, it has been widely argued that the brain is especially prone to oxidative damage, as attributable by the brain being(1) rich in peroxidizable fatty acids, (2) poor in catalase activity and having only moderate amounts of SOD and GSH-Px, and (3) rich in iron in several areas, which facilitates the production of highly reactive hydroxyl radicals $[9,11]$. In $\mathrm{BD}$, accumulating evidence from a range of studies using post-mortem brain tissue and peripheral blood samples has demonstrated increased oxidative damage to cellular macromolecules. These studies have also demonstrated a decrease in antioxidant capacity. Relevant to current and future development of therapeutics, there have been numerous reports of mood-stabilizing drugs producing neuroprotective effects against oxidative damage and increased antioxidant expression and activity.

\section{Oxidative Stress in BD}

Direct evidence of increased oxidative stress has come from studies utilizing post-mortem brain tissue to measure markers of oxidative damage to cellular macromolecules. In 2009, Wang et al. [12] reported that 4-hydroxynonenal (4-HNE) protein adducts are significantly increased in postmortem Anterior Cingulate Cortex (ACC) of subjects diagnosed with either $\mathrm{BD}$ or schizophrenia when compared to nonpsychiatric populations. These adducts are known to be a major product of lipid peroxidation, and are able to induce cytotoxic effects and disturb cellular function when they accumulate in excess. Therefore this finding suggests that oxidative damage to lipids and proteins is associated with $\mathrm{BD}$ and schizophrenia. It is very likely that ACC pathology is involved in $\mathrm{BD}$ symptomatology, as this structure has a vast array of connections to other frontal and limbic areas and contributes to processing of cognitive, emotional, and attention functions [13]. Interestingly, subjects without medication had higher levels of 4-HNE protein adducts compared to the total $\mathrm{BD}$ patient group, which may indicate an underlying marker of pathology in $\mathrm{BD}$ [12], although this remains to be validated in future studies with larger sample sizes. The authors also report a negative correlation between 4-HNE and $\mathrm{pH}$, which may be indicative of a relationship between oxidative stress and mitochondrial dysfunction. More specifically, the mitochondrial dysfunction may lead to both an increase in ROS production and a shift of energy production from oxidative phosphorylation in the ETC towards glycolysis and lactic acid production.

It has also been found that levels of protein carbonylation and 3-nitrotyrosine (3-NT) are increased in prefrontal cortex tissue of BD subjects [14]. Protein carbonylation is an oxidative process where ROS react to form carbonyl groups into the side chains of amino acids in proteins. 3-NT is another marker for protein oxidation, and is a result of tyrosine residues being nitrated by the Reactive Nitrogen Species (RNS) peroxynitrite [9]. Interestingly, another study with hippocampal tissue of $\mathrm{BD}$ patients showed increases in neuronal nitric oxide synthase I, the enzyme that generates nitric oxide, the precursor to peroxynitrite
[15]. Oxidation of proteins can lead to damaging effects through the formation of deleterious intermolecular aggregates and the alteration of protein function. It has also been report that carbonylation and 3-NT levels were correlated with decreases in ETC complex I activity, suggesting that increases in oxidative dysfunction may be coming from mitochondrial dysfunction, specifically excessive leakage of electrons at complex I [14]. Indeed, protein oxidation from peroxynitrite can result in inhibition of complex I activity, as a study by Naoi et al. [16] demonstrated increases in 3-NT levels of complex I subunits compared to other ETC complexes in SH-SY5Y neuroblastoma cells incubated with peroxynitrite. Taken together, this evidence shows that oxidative damage to proteins is elevated in $\mathrm{BD}$, and that it is likely to be interrelated with mitochondrial dysfunction.

Increased oxidative damage to nucleic acids has recently been observed in a post-mortem brain study of BD patients [17]. In the CA1, CA3, and dentate gyrus regions of the hippocampus, oxidative damage to nucleic acids was greater in $\mathrm{BD}$ subjects compared to controls. The hippocampus is best known for involvement in memory formation, but it is also connected with other limbic structures in order to regulate emotion. Moreover, hippocampus has been shown to be susceptible to damage from stress effects, as well as having volumetric abnormalities in BD patients [18]. RNA and DNA can be oxidized by ROS, with guanine residues most sensitive to attack compared to other bases. When these residues react with ROS, 8-oxo,7, 8,-dihydro guanosine (8-OHG) is produced in RNA and 8-oxo-7, 8-dihydro-2deoxy guanosine (8-OHdG) in DNA. In this study, oxidative damage was quantified through performance of immunohistochemistry with a monoclonal antibody recognizing both 8 -OHG and 8-OHdG, and increases were found in BD subjects, along with major depression and schizophrenia subjects, when compared to controls. The study authors discuss the possibility of increased susceptibility to oxidative damage to RNA compared to DNA because of the fact that RNA are single stranded and without the protection from hydrogen bonds found in DNA, which is double stranded. Oxidatively modified RNA may cause downstream effects through errors in translation and altered or reduced protein expression. DNA fragmentation was also found to be increased in non-GABAergic neurons in BD [19], and it is suggested that this may confer vulnerability to oxidative stress and excytotoxicity [20]. Although these studies utilizing postmortem brain tissue from patients cannot rule out the effects of medication, substantial evidence from in vivo and in vitro studies suggests a neuroprotective role against oxidative stress in the major pharmacological treatments of $\mathrm{BD}$. Thus it appears more likely that the significant differences found are due to an underlying pathology rather than a consequence of medication.

Deficiencies in brain antioxidants may also make significant contributions to increases in oxidative stress. Glutathione (GSH), the major free radical scavenger in the brain, was found to be lower in prefrontal regions of patients with $\mathrm{BD}$, major depressive disorder and schizophrenia [21]. It has also been reported that gene expression of antioxidant enzymes such as SOD1, catalase, GSH-Px4, and GST is down-regulated in the hippocampus [22]. Fullerton and colleagues [23] also found that genes for SOD2 and GSH-Px3 are possible risk factors for $\mathrm{BD}$. By targeting candidate genes in the oxidative stress pathway, the authors found that haplotypes within the SOD2 gene are associated with $\mathrm{BD}$ and interaction between SOD2 and GSH-Px3 at the haplotype and genotype level further increased this risk. Impairments in antioxidant defense systems in $\mathrm{BD}$ may indicate a decreased ability to neutralize ROS accumulation and infer susceptibility to oxidative stress. 
Increases in peripheral biomarkers of oxidative stress have also been consistently reported in the literature. These were in biological samples of plasma, serum, white blood cells, red blood cells, or platelets from patients with BD. Studies have indicated significant increases in lipid peroxidation [24-26] and nitric oxide, a highly reactive oxidant molecule [24,27-29], along with DNA damage associated with oxidative stress [30], increased protein carbonyl content [31], and several antioxidant enzymes $[25,27,32]$. Some discrepancies in the literature exist surrounding SOD antioxidant levels being increased or decreased, which may reflect fluctuations in response to state dependent changes in oxidant levels $[24,27,33]$. Number of manic episodes was found to be correlated to serum nitric oxide levels [24], indicating that oxidative stress may be a trait marker of the disease, and that the chronic nature of the illness could lead to long term accumulation of oxidative stress, resulting in the poorer outcomes associated with length of disease and number of mood episodes [34]. Moreover, Andreazza et al. [30] found that increased DNA damage indicative of oxidative stress was associated with severity of mood symptoms. Importantly, increases in protein carbonylation were detectable in early stages of the illness, as reported in a recent population based study of young adults [35]. Research has also suggested that there may be particular oxidative imbalances present during active phases of BD, as Andreazza et al. [25] found increases in SOD activity only in patients during depressed or manic states, but not in euthymic episodes.

It has also been reported that mania is associated with higher lipid peroxidation levels than any other phase of the illness [36]. In a recent study by Kapczinski et al. [31], such state dependent differences were examined in greater detail. Here they observed that manic and depressive episodes were distinguishable from control conditions by increased protein carbonylation and lipid peroxidation. 3-NT was elevated compared to controls only in depression [31]. Interestingly; a study by Yumru et al. [37] demonstrated that analyses of various markers of oxidative imbalance in $\mathrm{BD}$ patients had some ability to distinguish between bipolar subtype diagnoses. While peripheral samples suggest oxidative stress in the pathophysiology of $\mathrm{BD}$, it is still unclear how blood biomarkers can specifically describe the state of oxidative stress in the brain. Thus, interpretation of these findings remains limited. Nonetheless, these studies have provided a valuable contribution by studying the relationship between oxidative stress and more particular and dynamic clinical factors such as illness duration, type of mood episode, and effects of medication. All together, amongst a wide range of patient populations, using different biological samples and experimental measures, these studies have generated a large body of literature to implicating oxidative stress in the pathophysiology of $\mathrm{BD}$ (Table 1).

Animal studies also provide evidence of oxidative stress in $\mathrm{BD}$, although the interpretations arelimited given thelack of a comprehensive model of the disease. Amphetamine induced hyperactivity is the most widely used animal model of mania, and as such is commonly used to study the manic component of BD. Studies have reported that repeated amphetamine administration was associated with increases in superoxide production [38], and protein and lipid oxidative damage in rat brain [39], with longer periods of exposure being positively correlated with oxidative stress. Another study by the same group found that the same model resulted in SOD and catalase activity decreases [40]. It has also been found that amphetamine treatment can induce increased peripheral and hippocampal DNA damage that is also correlated with increases in lipid peroxidation [41]. Tan et al. [42] also found that chronic amphetamine treatment increased 4 -HNE protein adduction, particularly 4 -HNE adduction with vesicular monoamine transporter 2 (VMAT2) in frontal cortex of rat brain. Monoamine neurotransmitters are involved in the etiology and pathology of bipolar disorder and other psychiatric diseases, and also contribute significantly to amphetamine-induced behavioral effects. Vesicular monoamine transporter 2 (VMAT2) is critical in packaging monoamine neurotransmitters. Similar results were found in an animal model of mania induced by ouabain, a $\mathrm{Na}+\mathrm{K}+-\mathrm{ATPase}$ inhibitor, which mimics the hyperactivity and the sodium pump hypoactivity found in BD [43]. Specifically, this model can demonstrate increases in TBARS, superoxide production, and protein carbonyl content [44-46]. Evidence for oxidative stress also exists in animal models of depression, although these usually take place in the context of studying major depressive disorder. Nonetheless, phenotypic expression of unipolar and bipolar depression is very similar, and animal models of depression are not distinguished for any particular type of depression. Lucca and colleagues [47] used a chronic mild stress model of depression on rats and found increases in superoxide generation in the hippocampus and TBARS in the cortex. Using the same model, Eren et al. [48] reported a decrease in antioxidants GSH-Px, glutathione, and vitamin $\mathrm{C}$ in rat cortex, and Ejchel-Cohen et al. [49] reported decreases in the antioxidant GST gene expression. Chronic stress models typically produce depressive symptoms in rats, such as anhedonia, weight loss, and decreased locomotors activity. Other studies using prolonged or chronic stress in animals have reported various increases in ROS and oxidative damage [50-52].

\section{Treatment of Mood Stabilizing Drugs}

Mood stabilizing drugs are medications for the treatment of $\mathrm{BD}$ and are useful for the treatment of acute manic episodes and for prophylaxis against future episodes. These drugs include lithium, often considered the "gold standard" mood stabilizing drug, anticonvulsant medications such as valproate, carbamazepine, lamotrigine, and atypical antipsychotics such as olanzapine. Despite the extended history of use in patients, as well as many years of research, the mechanism of action of these treatments is still unclear. A growing body of evidence shows that chronic treatment with mood stabilizing drugs is neuroprotective against oxidative stress both in vitro and in vivo [53] and this neuroprotective mechanism is currently undergoing extensive study. It has been reported that chronic treatment with the mood stabilizing drug lithium or valproate significantly inhibited oxidative damage to lipids and proteins induced by various insults in primary cultured rat cerebral cortical cells [54,55]. Treatment with lithium or valproate werealso shown to inhibit $\mathrm{H}_{2} \mathrm{O}_{2}$-induced and complex I inhibitor rotenone-induced cytochrome c release, caspase- 3 activation, and cell death in human neuroblastoma cells and in murine hippocampal cells $[56,57]$.

To further elucidate the mechanisms of action for these drugs, Cui et al. [57] showed that these drugs increase the levels of the antioxidant GSH and the expression of glutamate-cysteine ligase, the rate-limiting enzyme in GSH synthesis. Similar results were demonstrated with the mood stabilizing drugs lamotrigine and carbamazepine [57]. Lithium and valproate were also found to bolster antioxidant defenses through the regulation of GST. It was found that lithium increased mRNA expression of the M1,M3, M5, and A4 isoenzymes, while valproate increased levels of M1 and A4 but decreased A3 [58,59]. These findings were complimented by other reports showing lithium treatment in rats to increase brain SOD and GSH-Px activity [60] and also in an aggregate measure of total antioxidant activity [61]. Thus, current mood stabilizing treatments may exert their therapeutic effects at least in part by combating oxidative stress and strengthening antioxidant defense mechanisms. 
Further evidence is provided by animal studies in vivo. Frey et al. [62] reported that chronic treatment with lithium and valproate inhibits amphetamine-induced hyperactivity and lipid peroxidation in rat brain. Inhibition of both hyperactive mania-like behaviour and oxidative stress suggests that this anti-oxidative stress effect may play an important role in the therapeutic effect of lithium and valproate. Similarly, lithium and valproate were able to modulate oxidative balance and prevent associated DNA damage in this animal model [41]. A study by Jornada et al. [44] showed that lithium and valproate reversed and prevented oxidative damage and production of superoxide in an animal model of mania using ouabain, as well as increasing catalase activity. These findings have therapeutic relevance because these drugs can also reverse the ouabain induced hyperactive behavior in an open field test [63]. It has also been found that when aluminium administration in rats causes ROS production and increased lipid peroxidation, these effects were decreased when followed by lithium supplementation [64]. The same study reported that changes in antioxidant enzymes by aluminium were normalized by lithium treatment. Most recently, chronic lithium treatment has been found to inhibit 4-HNE-protein adduction [42]. Repeated amphetamine stimulation significantly increased 4-HNE-VMAT2 adducts, while chronic lithium treatment reduced amphetamine-increased 4-HNEVMAT2 adducts in rat frontal cortex. Taken together, these findings suggest that prevention of oxidative stress may contribute at least in part to the pharmacological action of mood stabilizing drugs for the treatment of $\mathrm{BD}$.

Mood stabilizing therapy has also shown to decrease oxidative

\begin{tabular}{|c|c|c|c|c|c|}
\hline Reference & Patients/Controls & Sample & Results & Medication, drugs/alcohol & Mood Status \\
\hline Oliveira et al. [15] & $15 / 15$ & $\begin{array}{l}\text { Postmortem brain - hip- } \\
\text { pocampus }\end{array}$ & $\uparrow n N O S$ & $\begin{array}{l}\text { Lithium subjects higher in CA3 region } \\
\text { than non-lithium, no effect from other } \\
\text { medications }\end{array}$ & N/A \\
\hline Wang et al. [12] & $15 / 15$ & $\begin{array}{l}\text { Postmortem brain - hip- } \\
\text { pocampus }\end{array}$ & $\uparrow n N O S$ & $\begin{array}{l}\text { Lithium subjects higher in CA } 3 \text { region } \\
\text { than non-lithium, no effect from other } \\
\text { medications }\end{array}$ & N/A \\
\hline Andreazza et al. [14] & $15 / 15$ & Postmortem brain - PFC & $\uparrow P C C, 3-N T$ & No effect of medication on measures & N/A \\
\hline Che et al. [17] & $15 / 15$ & $\begin{array}{l}\text { Postmortem brain - hip- } \\
\text { pocampus }\end{array}$ & $\uparrow R N A$ oxidative damage & $\mathrm{N} / \mathrm{A}$ & N/A \\
\hline Gawryluk et al. [21] & $15 / 15$ & Postmortem brain - PFC & $\downarrow \mathrm{GSH}$ & No effect from drug/alcohol abuse & N/A \\
\hline Abdalla et al. [33] & $20 / 58$ & RBC & $\uparrow S O D$ & $\begin{array}{l}\text { No difference between lithium and } \\
\text { lithium+antipsychotic }\end{array}$ & N/A \\
\hline Savas et al. [24] & $44 / 21$ & Plasma & $\uparrow N O$ & N/A & N/A \\
\hline Rajekar et al. [32] & $10 / 31$ & RBC & $\downarrow S O D, C A T, \uparrow T B A R S$ & N/A & N/A \\
\hline Ozcan et al. [66] & $30 / 21$ & RBC & $\downarrow C A T, G S H-P x, N O \uparrow M D A$ & $\begin{array}{l}\text { After } 3 \text { months psychiatric inpatient } \\
\text { clinic, GSH-Px increased }\end{array}$ & $\mathrm{N} / \mathrm{A}$ \\
\hline Yanik et al. [28] & $43 / 31$ & Plasma & $\uparrow N O$ & $\mathrm{~N} / \mathrm{A}$ & N/A \\
\hline Savas et al. [24] & $27 / 20$ & Serum & $\uparrow N O, S O D$ & $\mathrm{~N} / \mathrm{A}$ & $\begin{array}{l}\text { Number of manic episodes } \\
\text { correlate with NO, not } \\
\text { SOD }\end{array}$ \\
\hline Andreazza et al. [25] & $85 / 32$ & Serum & $\begin{array}{l}\uparrow \text { TBARS, SOD, SOD:GSH- } \\
\text { Px+Cat }\end{array}$ & $\mathrm{N} / \mathrm{A}$ & $\begin{array}{l}\text { SOD, SOD:GSH-Px+Cat } \\
\text { effects in manic or depres- } \\
\text { sive phase }\end{array}$ \\
\hline Andreazza et al. [30] & $32 / 32$ & Serum & $\uparrow D N A$ damage & No effect of medication & $\begin{array}{l}\text { Depressive/manic states } \\
\text { correlate with damage }\end{array}$ \\
\hline $\begin{array}{l}\text { Machado-Vieira et al. } \\
\text { [65] }\end{array}$ & $30 / 30$ & Serum & $\uparrow N O$, SOD & N/A & $\begin{array}{l}\text { Currently euthymic. Manic } \\
\text { episodes correlated with } \\
\text { increasing NO }\end{array}$ \\
\hline $\begin{array}{l}\text { Gergerlioglu et al. } \\
\text { [29] }\end{array}$ & $29 / 30$ & Serum & $\uparrow N O, \downarrow S O D$ & $\begin{array}{l}\text { After } 30 \text { days of psychiatric hospital } \\
\text { treatment, SOD decreased, no differ- } \\
\text { ence in NO }\end{array}$ & $\begin{array}{l}\text { SOD negatively correlated } \\
\text { with number of manic epi- } \\
\text { sodes, correlation between } \\
\text { NO and delusions. }\end{array}$ \\
\hline Kunz et al. [36] & $83 / 32$ & Serum & $\uparrow S O D, T B A R S$ & $\mathrm{~N} / \mathrm{A}$ & $\begin{array}{l}\text { SOD with mania and } \\
\text { depression, not euthymic. } \\
\text { TBARS with all phases. }\end{array}$ \\
\hline Selek et al. [27] & $30 / 30$ & Serum & $\downarrow \mathrm{SOD}, \uparrow \mathrm{NO}$ & $\begin{array}{l}\text { Degree of normalization after } 30 \text { days } \\
\text { hospitalization with drug treatments }\end{array}$ & $\begin{array}{l}\text { No correlation with number } \\
\text { of any type of episode }\end{array}$ \\
\hline Yumru et al. [37] & $94 / 41$ & Plasma & $\begin{array}{l}\uparrow \text { Total oxidant, Total anti- } \\
\text { oxidant, Oxidative stress } \\
\text { (oxidant/antioxidant) }\end{array}$ & $\mathrm{N} / \mathrm{A}$ & $\mathrm{N} / \mathrm{A}$ \\
\hline Kapczinski et al. [83] & $80 / 60$ & Serum & $\uparrow P C C$, TBARS & $\mathrm{N} / \mathrm{A}$ & $\begin{array}{l}\text { Depression and mania } \\
\text { associated with PCC, } \\
\text { TBARS, not euthymia. }\end{array}$ \\
\hline Magalhães et al. [71] & $55 / 94$ & Serum & $\uparrow P C C$ & Current use of medication not correlated & N/A \\
\hline Banerjee et al. [26] & $73 / 35$ & Serum & $\uparrow$ TBARS & $\begin{array}{l}\text { TBARS lower in lithium treated vs. } \\
\text { lithium naive }\end{array}$ & $\mathrm{N} / \mathrm{A}$ \\
\hline
\end{tabular}

Table 1: Studies of oxidative stress in Bipolar Disorder patients. If available, findings of associated variables of mood stabilizing medications, alcohol and drugs of abuse, and different mood episodes with oxidative stress measures are presented. Brain samples: Anterior cingulate cortex (ACC), Prefrontal cortex (PFC). Peripheral samples: Red blood cells (RBC). Reactive Oxygen Species: Nitric Oxide (NO), Neuronal nitric oxide synthase (nNOS). Oxidative damage to proteins: Protein carbonyl content (PCC), 3-Nitrotyrosine (3-NT). Oxidative damage to lipids: Thiobarbituric acid reactive substances (TBARS), 4-hydroxynonenal (4-HNE). Antioxidants: Catalase (CAT), Glutathione (GSH), Glutathione peroxidase (GSH-Px), Superoxide dismutase (SOD). 
stress markers in peripheral samples of human patients. MachadoVieira et al. [65] reported that acute treatment with lithium was able to normalize SOD/CAT ratios and reduce lipid peroxidation levels. A longer study of treatment effects was conducted on $30 \mathrm{BD}$ patients admitted to hospital, and showed that there was reduction of nitric oxide levels and increases in SOD activity between the 1st and 30th day of admission [27]. These results point to the possibility of oxidative stress alleviation with mood stabilizing treatments, although the study did note that SOD levels were not able to fully match control subject levels after 30 days, indicating a trait impairment in antioxidant capacity and possible predisposition to oxidative stress in BD.A similar study by Ozcan et al. [66] was conducted over an even longer period of 3 months, but with much smaller sample size, and observed a higher amount of GSH-Px activity in the post-treatment group compared to pre-treatment and control groups. Moreover, lithium alone or in combination with olanzapine appears to relieve lipid peroxidation and increase total antioxidant status [67]. In a study of healthy volunteers given therapeutic doses of lithium for 2-4 weeks, results showed decreases in hydrogen peroxide levels [68]. These studies are useful in providing evidence for the therapeutic effect of antioxidant properties in current mood stabilizing treatments. The sum of the evidence available shows that current mood stabilizing drug treatments have a neuroprotective effect against oxidative stress, and can modulate a variety of antioxidant pathways in the cell (Figure 1).

The possibility of novel drug treatments for BD through the alleviation of oxidative stress has been supported by some human studies. In a double-blind randomized placebo-controlled trial, Berk et al. [69] used treatment with N-Acetyl Cysteine (NAC) in BD patients in their maintenance phase. NAC is an acetylated derivative of cysteine, which is the rate-limiting precursor in GSH production [70]. This study showed that NAC caused a significant improvement in assessments of depression and global occupational and social functioning. More recent reports showed that in a small sample of bipolar II disorder patients, full remission of symptoms was significantly higher in the NAC group compared to the placebo group [71]. Using NAC as adjunctive treatment for $\mathrm{BD}$ leads to reductions of depression scores in patients currently suffering from depressive phases [72]. These studies are consistent with animal studies showing that NAC can reduce amphetamine induced hyperactivity manic-like behaviour, behavioral sensitization and striatal dopamine depletion [73], and can boost GSH levels as well [74].

\section{Implications of Oxidative Stress in the Pathophysiology of BD}

While the evidence for oxidative stress in BD continues to build, the implications of these findings to the overall pathophysiology of the illness still remain unclear. The significance of oxidative stress as a component of many disease processes in the central nervous system is increasingly recognized. Oxidative stress in the brain is seen in neurodegenerative disorders, Parkinson's disease and Alzheimer's disease. Many neurodegenerative disorders are strongly associated with increasing age [75], which attributes the precipitation of disease to gradual, long term accumulation of oxidative damage, finally causing neuronal loss in specific brain regions. However, onset of BD typically occurs in late adolescence or early adulthood [76]. BD is not as progressive as neurodegenerative disorders. Although less evidence suggests neuronal loss in $\mathrm{BD}$, milder oxidative stress in this disorder may further modify various molecules such as synaptic proteins, enzymes and components of intracellular signaling. Oxidative modifications of these molecules that have been found in BD could affect neurotransmission and impair neuroplasticity in brain regions related to mood regulation.

Research on the neurobiology of $\mathrm{BD}$ has shifted focus towards more enduring cellular and molecular changes in BD. These changes in cellular structure, function, growth and development are

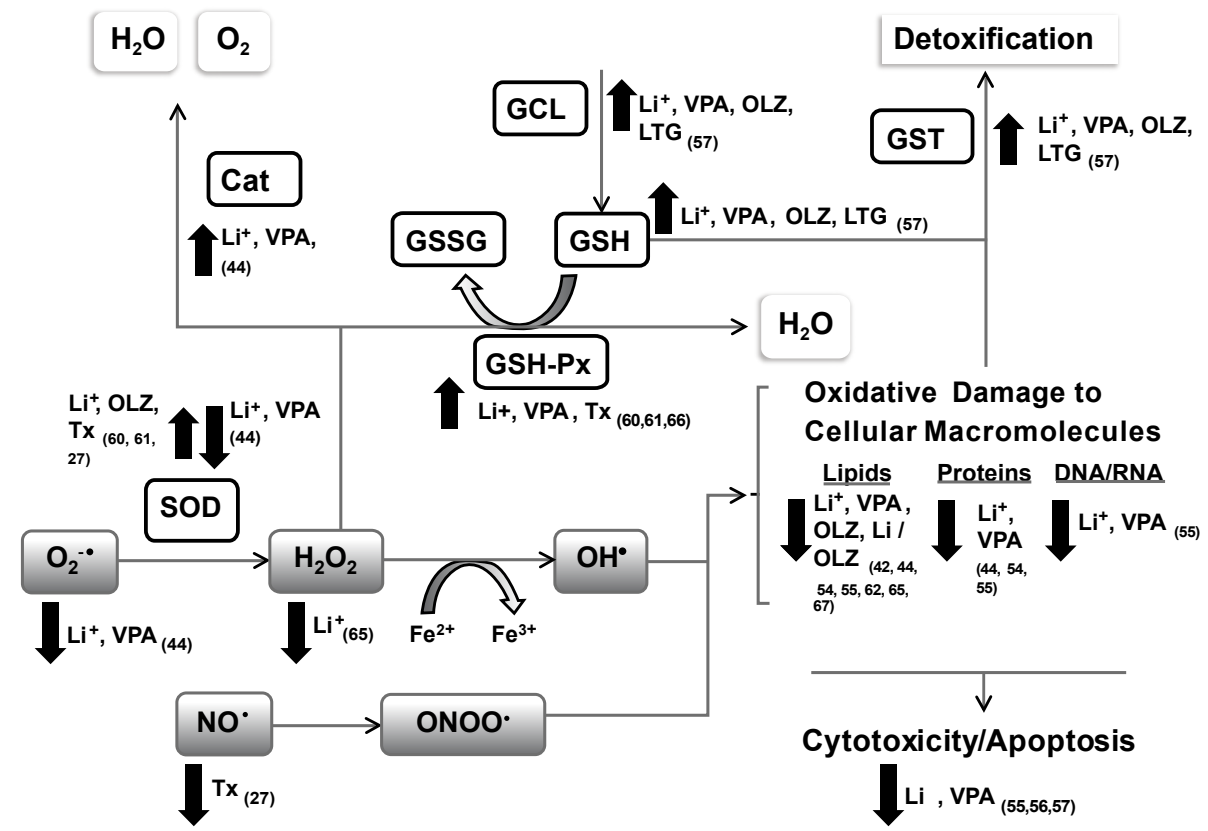

Figure 1: Antioxidant mechanisms of mood stabilizers. Arrows represent increases or decreases in expression or activity due to stated mood-stabilizing drugs, numbers as reference citations. Superoxide radical $\left(\mathrm{O}_{2} \cdot \bullet\right)$, hydrogen peroxide $\left(\mathrm{H}_{2} \mathrm{O}_{2}\right)$, hydroxyl radical $\left(\mathrm{OH}^{\bullet}\right)$, nitric oxide (NO•), peroxynitrite $(\mathrm{ONOO})$, superoxide dismutase (SOD), catalase (Cat), glutathione (GSH), glutathione peroxide (GSH-Px), glutathione disulfide (GSSG), glutamyl-cysteine ligase (GCL), glutathione-S-transferase (GST). Mood stabilizers: Lithium (Li ${ }^{+}$, valproate (VPA), olanzapine (OLZ), lamotrigine (LTG), Individualized psychiatric treatment in humans (Tx). 
characterized as mechanisms of neuroplasticity, and studies have accumulated to implicate dysfunction in these processes in BD [77]. Indeed, a recent genome-wide association study of $\mathrm{BD}$ revealed that most of the highly significant associations were implicated in signaling cascades of plasticity [78]. It has been proposed that abnormalities in neuroplasticity lead to maladaptive developments in neural circuits, affecting the information processing that mediates various facets of $\mathrm{BD}$ symptomatology $[77,79]$. The BDNF polymorphism gene (Val66Met) has been proposed to be associated with susceptibility to BD [80] and is said to alter the intracellular trafficking and activity-dependent secretion of BDNF [81]. This seems to be in line with other studies reporting BDNF decreases in serum of BD patients during manic and depressive phases [82]. Interestingly, Kapczinski et al. [83] showed that serum TBARS was negatively correlated with BDNF levels. Another study using peripheral biomarkers showed that BD patients showed increased oxidative stress and decreased neuron-specific endolase, a neuronal glycolytic enzyme known to mediate neuroplastic pathways and cell survival [65], although the relationship between these variables were not analyzed. An animal study by $\mathrm{Wu}$ et al. [84] showed that oxidative stress is correlated with BDNF reductions, as well as reductions in cyclic AMP responsive element binding protein and synapsin I molecules that are involved in cellular plasticity cascades. Such research suggests that oxidative stress may play a role in the abnormal neuroplastic processes found in BD pathophysiology.

Increases in levels of ROS are likely due in large part to mitochondrial dysfunction. Imaging studies through magnetic resonance spectroscopy have demonstrated that the energy metabolism within the brain appears to be abnormalin $\mathrm{BD}$ patients, inferring mitochondrial dysfunction [85-87]. Concurrent with these studies has been genetic research highlighting increases in mitochondrial DNA deletions and mutations and altered expression of mitochondrial proteins $[88,89]$. While mitochondrial dysfunction has a myriad of maladaptive effects on the cell, of particular interest are findings of defects in the ETC, which is the primary site of electron leakage that occurs during oxidative phosphorylation. Along with DNA microarray analyses that have identified decreased expression of mRNAs that code for ETC complexes [90,91], postmortem brain tissue of BD patients also shows decreased levels of complex I subunit expression and impaired functionality [14]. Aberrant functioning in mitochondria is observed to increase production of ROS, and it is well understood that electrons are provided to form these free radicals when they are leaked from the ETC $[92,93]$. Mounting evidence suggests that mitochondria are directly involved in processes of synaptic plasticity. Mitochondria are enriched in presynaptic terminals, and play important roles in neurotransmission via energy production. In addition, mitochondria buffer the levels of calcium [94]. Calcium influx precedes neurotransmitter release and is necessary for vesicle docking and exocytosis. Mitochondrial dysfunction may be responsible for more pronounced calcium spikes and abnormal neurotransmitter release [95]. Deficiencies in ATP production, seen in $\mathrm{BD}$, can impair the energy demanding processes of vesicle docking, fusion, and endocytosis.

\section{Conclusions}

As the neurobiology of $\mathrm{BD}$ continues to be elucidated, it has become clearer that oxidative stress likely plays an important role in the development of the illness. Studies of postmortem brain tissue have found evidence of oxidative damage to proteins, nucleic acids, and lipids, as well as decreased antioxidants, suggesting the presence of oxidative stress as a major component of $\mathrm{BD}$ pathophysiology. Other lines of evidence from animal model studies and peripheral blood studies of BD patients also converge to support this notion. Damage to the biochemical properties of cellular macromolecules is likely to underlie functional abnormalities in the brain, particularly the impairments in neuroplasticity that have been highlighted in the recent literature. Studies of pharmacological mechanisms of mood stabilizing treatment have also provided a large body of research supporting the therapeutic benefits of neuroprotection against oxidative stress. These findings contribute to our understanding of this complex and multidimensional disorder, and may reveal putative targets for novel drug development. Such efforts provide hope for discovering better treatments and outcomes for those with BD.

\section{References}

1. Eastwood SL, Harrison PJ (2001) Synaptic pathology in the anterior cingulate cortex in schizophrenia and mood disorders. A review and a Western blot study of synaptophysin, GAP-43 and the complexins. Brain Res Bull 55: 569-578.

2. Pralong E, Magistretti P, Stoop R (2002) Cellular perspectives on the glutamatemonoamine interactions in limbic lobe structures and their relevance for some psychiatric disorders. ProgNeurobiol 67: 173-202.

3. Knable MB, Barci BM, Webster MJ, Meador-Woodruff J, Torrey EF (2004) Molecular abnormalities of the hippocampus in severe psychiatric illness: postmortem findings from the Stanley Neuropathology Consortium. Mo Psychiatry 9: 609-620.

4. Chen CH, Suckling J, Lennox BR, Ooi C, Bullmore ET (2011) A quantitative meta-analysis of fMRI studies in bipolar disorder. Bipolar Disord 13: 1-15.

5. Rajkowska G, Halaris A, Selemon LD (2001) Reductions in neuronal and glial density characterize the dorsolateral prefrontal cortex in bipolar disorder. Bio Psychiatry 49: 741-752.

6. Benes FM, Vincent SL, Todtenkopf M (2001) The density of pyramidal and nonpyramidal neurons in anterior cingulate cortex of schizophrenic and bipolar subjects. Biol Psychiatry 50: 395-406.

7. Clark L, Chamberlain SR, Sahakian BJ (2009) Neurocognitive mechanisms in depression: Implications for treatment. Ann Rev Neurosci 32: 57-74

8. Maher P, Schubert D (2000) Signaling by reactive oxygen species in the nervous system. Cell Mol Life Sci 57: 1287-1305.

9. Halliwell B (1997) What nitrates tyrosine? Is nitrotyrosine specific as a biomarker of peroxynitrite formation in vivo? FEBS Lett 441: 157-160.

10. Fridovich I (1978) The biology of oxygen radicals. Science 201: 875-80.

11. Floyd RA (1999) Antioxidants, oxidative stress, and degenerative neurological disorders. Proc Soc Exp Biol Med 222: 236-245.

12. Wang JF, Shao L, Sun X, Young LT (2009) Increased oxidative stress in the anterior cingulate cortex of subjects with bipolar disorder and schizophrenia. Bipolar Disord 11: 523-529.

13. Allman JM, Hakeem A, Erwin JM, Nimchinsky E, Hof P (2001) The Anterior Cingulate Cortex: The Evolution of an Interface between Emotion and Cognition. Ann N Y AcadSci 935: 107-117.

14. Andreazza AC, Shao L, Wang JF, Young LT (2010) Mitochondrial complex activity and oxidative damage to mitochondrial proteins in the prefrontal cortex of patients with bipolar disorder. Arch Gen Psychiatry 67: 360-368.

15. Oliveira RM, Guimarães FS, Deakin JF (2008) Expression of neuronal nitric oxide synthase in the hippocampal formation in affective disorders. Braz J Med Biol Res 41: 333-341.

16. Naoi M, Maruyama W, Shamoto-Nagai M, Yi H, Akao Y, et al. (2005) Oxidative stress in mitochondria: decision to survival and death of neurons in neurodegenerative disorders. Mol Neurobiol 31:81-93.

17. Che Y, Wang JF, Shao L, Young T (2010) Oxidative damage to RNA but not DNA in the hippocampus of patients with major mental illness. J Psychiatry Neurosci 35: 296-302.

18. Beyer JL, Krishnan KR (2002) Volumetric brain imaging findings in mood disorders. Bipolar Disord 4: 89-104.

19. Buttner N, Bhattacharyya S, Walsh J, Benes FM (2007) DNA fragmentation 
is increased in non-GABAergic neurons in bipolar disorder but not in schizophrenia. Schizophr Res 93: 33-41.

20. Coyle JT, Puttfarcken P (1993) Oxidative stress, glutamate, and neurodegenerative disorders. Science 262: 689-695.

21. Gawryluk JW, Wang JF, Andreazza AC, Shao L, Young LT (2011) Decreased levels of glutathione, the major brain antioxidant, in post-mortem prefrontal cortex from patients with psychiatric disorders. Int $\mathrm{J}$ Neuropsychopharmaco 14: $123-130$

22. Benes FM, Matzilevich D, Burke RE, Walsh J (2006) The expression of proapoptosis genes is increased in bipolar disorder, but not in schizophrenia. Mol Psychiatry 11: 241-251

23. Fullerton JM, Tiwari Y, Agahi G, Heath A, Berk M, et al. (2010) Assessing oxidative pathway genes as risk factors for bipolar disorder. Bipolar Disord 12: $550-556$

24. Savas HA, Gergerlioglu HS, Armutcu F, Herken H, Yilmaz HR, et al. (2006) Elevated serum nitric oxide and superoxide dismutase in euthymic bipolar patients: impact of past episodes. World J Biol Psychiatry 7: 51-55.

25. Andreazza AC, Cassini C, Rosa AR, Leite MC, de Almeida LM, et al. (2007) Serum S100B and antioxidant enzymes in bipolar patients. J Psychiatr Res 41: $523-529$.

26. Banerjee U, Dasgupta A, Rout JK, Singh OP (2012) Effects of lithium therapy on $\mathrm{Na+-K+-ATPase}$ activity and lipid peroxidation in bipolar disorder. Prog Neuropsychopharmacol Biol Psychiatry 37: 56-61.

27. Selek S, Savas HA, Gergerlioglu HS, Bulbul F, Uz E, et al. (2008) The course of nitric oxide and superoxide dismutase during treatment of bipolar depressive episode. J Affect Disord 107: 89-94.

28. Yanik M, Vural H, Tutken H, Zoroğlu SS, Savas HA, et al. (2004) The role of arginine-nitric oxide pathway in the pathogenesis of bipolar affective disorder Eur Arch Psychiatry Clin Neurosci 254: 43-47.

29. Gergerlioglu HS, Savas HA, Bulbul F, Selek S, Uz E, et al. (2007) Changes in nitric oxide level and superoxide dismutase activity during antimanic treatment. Prog Neuropsychopharmacol Biol Psychiatry 31: 697-702.

30. Andreazza AC, Frey BN, Erdtmann B, Salvador M, Rombaldi F, et al. (2007) DNA damage in bipolar disorder. Psychiatry Res 153: 27-32.

31. Kapczinski F, Dal-Pizzol F, Teixeira AL, Magalhaes PV, Kauer-Sant'Anna M et al. (2011) Peripheral biomarkers and illness activity in bipolar disorder. J Psychiatry Res 45: 156-161.

32. Rajekar PK, Hinge A, Hegde MV, Ghate M, Kale A, et al. (2003) Decreased antioxidant enzymes and membrane essential polyunsaturated fatty acids in schizophrenic and bipolar mood disorder patients. Psychiatry Res 121: 109122

33. Abdalla DSP, Monteiro HP, Oliveira JAC, Berchara EJH (1986) Activities of superoxide dismutase and glutathione peroxidase in schizophrenia and manicdepressive patients. Clin Chem 32: 805-807.

34. Berk M, Kapczinski F, Andreazza AC, Dean OM, Giorlando F, et al. (2010) Pathways underlying neuroprogression in bipolar disorder: focus on inflammation, oxidative stress and neurotrophic factors. Neurosci Biobehav Rev 35: 804-817.

35. Magalhães PV, Jansen K, Pinheiro RT, Colpo GD, de Motta LL, et al. (2011) Peripheral oxidative damage in early-stage mood disorders: A nested population-based case-control study. Int J Neuropsychopharmacol 19: 1-8.

36. Kunz M, Gama CS, Andreazza AC, Salvador M, Cereser KM, et al. (2008) Elevated serum superoxide dismutase and thiobarituric acid reactive substances in different phases of bipolar disorder and schizophrenia. Prog Neuropsychopharmacol Biol Psychiatry 32: 1677-1681.

37. Yumru M, Savas HA, Kalenderoglu A, Bulut M, Celik H, et al. (2009) Oxidative imbalance in bipolar disorder subtypes: A comparative study. Prog Neuropsychopharmaco Biol Psychiatry 33: 1070-1074.

38. Frey BN, Valvassori SS, Gomes KM, Martins MR, Dal-Pizzol F, et al. (2006) Increased oxidative stress in submitochondrial particles after chronic amphetamine exposure. Brain Res 1097: 224-229.

39. Frey BN, Martins MR, Petronilho FC, Dal-Pizzol F, Quevedo J, et al. (2006) Increased oxidative stress after repeated amphetamine exposure: Possible relevance as a model of mania. Bipolar Disord 8: 275-280.
40. Frey BN, Valvassori SS, Reus GZ, Martins MR, Petronilho FC, et al. (2006) Changes in antioxidant defense enzymes after D-amphetamine exposure: Implications as an animal model of mania. Neurochem Res 31: 699-703.

41. Andreazza AC, Kauer-Sant'Anna M, Frey BN, Stertz L, Zanotto C, et al. (2008) Effects of mood stabilizers on DNA damage in an animal model of mania. J Psychiatry Neurosci 33: 516-524.

42. Tan H, Young LT, Shao L, Che Y, Honer WG, et al. (2011) Mood stabilize lithium inhibits amphetamine-increased 4-hydroxynonenal-protein adducts in rat frontal cortex. Int J Neuropsychopharmacol 23: 1-11.

43. Looney SW, el-Mallakh RS (1997) Meta-analysis of erythrocyte Na,K-ATPase activity in bipolar illness. Depress Anxiety 5: 53-65.

44. Jornada LK, Valvassori SS, Steckert AV, Moretti M, Mina F, Ferreira CL, et al. (2011) Lithium and valproate modulate antioxidant enzymes and prevent ouabain-induced oxidative damage in an animal model of mania. J Psychiatr Res 45:162-168.

45. Riegel RE, Valvassori SS, Elias G, Reus GZ, Steckert AV, et al. (2009) Animal model of mania induced by ouabain: Evidence of oxidative stress in submitochondrial particles of the brain. Neurochem Int 55: 491-495.

46. Riegel RE, Valvassori SS, Moretti M, Ferreira CL, Steckert AV, et al. (2010) Intracerebroventricular ouabain administration induces oxidative stress in the rat brain. Int J Devl Neuroscience 28: 233-237.

47. Lucca G, Comim CM, Valvassori SS, Reus GZ, Vuolo F, et al. (2009) Increased oxidative stress in submitochondrial particles into the brain of rats submitted to the chronic mild stress paradigm. J Psychiatr Res 43: 864-869.

48. Eren I, Naziroglu M, Demirdas A, Celik O, Uguz AC, et al. (2007) Venlafaxine modulates depression induced oxidative stress in brain and medulla of rat Neurochem Res 32: 497-505

49. Ejchel-Cohen TF, Wood GE, Wang JF, Barlow K, Nobrega JN, et al. (2006) Chronic restraint stress decreases the expression of glutathione S-transferase pi2 in the mouse hippocampus. Brain Res 1090: 156-162.

50. Lee YJ, Choi B, Lee EH, Choi KS, Sohn S (2006) Immobilization stress induces cell death through production of reactive oxygen species in the mouse cerebral cortex. Neurosci Lett 392: 27-31.

51. Madrigal JL, Olivenza R, Moro MA, Lizasoain I, Lorenzo P, et al. (2001) Glutathione depletion, lipid peroxidation and mitochondrial dysfunction are induced by chronic stress in rat brain. Neuropsychopharmacology 24: 420-429.

52. Manoli LP, Gamaro GD, Silveira PP, Dalmaz C (2000) Effect of chronic variate stress on thiobarbituric-acid reactive species and on total radical-trapping potential of distinct regions of rat brain. Neurochem Res 25: 915-921.

53. Rowe MK, Chuang DM (2004) Lithium neuroprotection: molecular mechanisms and clinical implication. Expert Rev Mol Med 18: 1-18.

54. Wang JF, Azzam JE, Young LT (2003) Valproate inhibits oxidative damage to lipid and protein in primary cultured rat cerebrocortical cells. Neuroscience 116 485-489.

55. Shao L, Young LT, Wang JF (2005) Chronic treatment with mood stabilizers lithium and valproate prevents excitotoxicity by inhibiting oxidative stress in rat cerebral cortical cells. Biol Psychiatry 58: 879-884.

56. Lai JS, Zhao C, Warsh JJ, Li PP (2006) Cytoprotection by lithium and valproate varies between cell types and cellular stresses. Eur J Pharmacol 539: 18-26.

57. Cui J, Shao L, Young LT, Wang JF (2007) Role of glutathione in neuroprotective effects of mood stabilizing drugs lithium and valproate. Neuroscience 144 1447-1453.

58. Wang JF, Shao L, Sun X, Young LT (2004) Glutathione S-transferase is a nove target for mood stabilizing drugs in primary cultured neurons. J Neurochem 88 : 1477-1484.

59. Shao L, Cui J, Young LT, Wang JF (2008) The effect of mood stabilizer lithium on expression and activity of glutathione s-transferase isoenzymes. Neuroscience 151: $518-524$

60. Shukla GS (1987) Mechanism of lithium action: in vivo and in vitro effects of alkali metals on brain superoxide dismutase. Pharmacol Biochem Behav 26 235-240.

61. de Vasconcellos AP, Nieto FB, Crema LM, Diehl LA, de Almeida LM, et al. (2006) Chronic lithium treatment has antioxidant properties but does not 
prevent oxidative damage induced by chronic variate stress. Neurochem Res 31: 1141-1151.

62. Frey BN, Valvassori SS, Réus GZ, Martins MR, Petronilho FC, et al. (2006) Effects of lithium and valproate on amphetamine-induced oxidative stress generation in an animal model of mania. J Psychiatry Neurosci 31: 326-332.

63. Jornada LK, Moretti M, Valvassori SS, Ferreira CL, Padilha PT, et al. (2010) Effects of mood stabilizers on hippocampus and amygdala BDNF levels in an animal model of mania induced by ouabain. J Psychiatr Res 44: 506-510.

64. Bhalla P, Dhawan DK (2009) Protective role of lithium in ameliorating the aluminium-induced oxidative stress and histological changes in rat brain. Cell Mol Neurobiol 29: 513-521.

65. Machado-Vieira R, Andreazza AC, Viale Cl, Zanatto V, Ceresar V Jr, et al. (2007) Oxidative stress parameters in unmedicated and treated bipolar subjects during initial manic episode: A possible role for lithium antioxidant effects. Neurosci Lett 421: 33-36.

66. Ozcan ME, Gulec M, Ozerol E, Polat R, Akyol O (2004) Antioxidant enzyme activities and oxidative stress in affective disorders. Int Clin Psychopharmacol 19: 89-95.

67. Aliyazicioglu R, Kural B, Colak M, Karahan SC, Ayvaz S, et al. (2007) Treatment with lithium, alone or in combination with olanzapine, relieves oxidative stress but increases atherogenic lipids in bipolar disorder. Tohoku J Exp Med 213:7987.

68. Khairova R, Pawar R, Salvadore G, Juruena MF, De Sousa RT, et al. (2012) Effects of lithium on oxidative stress parameters in healthy subjects. Mold Med Report 5: 680-682.

69. Berk M, Copolov DL, Dean O, Lu K, Jeavons S, et al. (2008) N-acetyl cysteine for depressive symptoms in bipolar disorder--a double-blind randomized placebo-controlled trial. Biol Psychiatry 64: 468-475.

70. Dodd S, Dean O, Copolov DL, Malhi GS, Berk M (2008) N-acetylcysteine for antioxidant therapy: pharmacology and clinical utility. Expert OpinBiolTher 8: 1955-1962.

71. Magalhães PV, Dean OM, Bush Al, Copolov DL, Malhi GS, et al. (2011) $\mathrm{N}$-acetyl cysteine add-on treatment for bipolar II disorder: A subgroup analysis of a randomized palacebo-controlled trial. J Affect Disord 129: 317-320.

72. Berk M, Dean O, Cotton SM, Gama CS, Kapczinski F, et al. (2011) The efficacy of $\mathrm{N}$-acetylcysteine as an adjunctive treatment in bipolar depression: An open label trial. J Affect Disord 135: 389-394.

73. Fukami G, Hashimoto K, Koike K, Okamura N, Shimizu E, et al. (2004) Effect of antioxidant $\mathrm{N}$-acetyl-L-cysteine on behavioral changes and neurotoxicity in rats after administration of methamphetamine. Brain Res 1016: 90-95.

74. Dean OM, van den Buuse M, Bush Al, Copolov DL, Ng F, et al. (2009) A role for glutathione in the pathophysiology of bipolar disorder and schizophrenia? Animal models and relevance to clinical practice. Curr Med Chem 16: 29652976.

75. Douglas PM, DillinA(2010)Protein homeostasis and aging in neurodegeneration J Cell Biol 190: 719-729.

76. Merikangas KR, Akiskal HS, Angst J, Greenberg PE, Hirschfeld RM, et al (2007) Lifetime and 12-month prevalence of bipolar spectrum disorder in the National Comorbidity Survey replication. Arch Gen Psychiatry 64: 543-552.

77. Schloesser RJ, Huang J, Klein PS, Manji HK (2008) Cellular plasticity cascades in the pathophysiology and treatment of bipolar disorder. Neuropsychopharmacology 33: 110-133.

78. Baum AE, Akula N, Cabanero M, Cardona I, Corona W, et al. (2008) A genomewide association study implicates diacylglycerol kinase eta (DGKH) and several other genesin the etiology of bipolar disorder. Mol Psychiatry 13: 197-207.

79. Einat H, Manji HK (2006) Cellular plasticity cascades: Genes-to-behavior pathways in animal models of bipolar disorder. Biol Psychiatry 59: 1160-1171.

80. Lohoff FW, Sander T, Ferraro TN, Dahl JP, Gallinat J, et al. (2005) Confirmation of association between the Val66Met polymorphism in the brain-derived

This article was originally published in a special issue, Reactive Oxygen Species: Oxidative damage \& Pathogenesis handled by Editor(s). Dr. Yong Wu, University of California, USA; Dr. M Salman Khan, Integral University, India neurotrophic factor (BDNF) gene and bipolar I disorder. Am J Med Genet B Neuropsychiatr Genet 139B: 51-53

81. Chen ZY, Patel PD, Sant G, Meng CX, Teng KK, et al. (2004) Variant brainderived neurotrophic factor (BDNF) (Met66) alters the intracellular trafficking and activity-dependent secretion of wild-type BDNF in neurosecretory cells and cortical neurons. J Neurosci 24: 4401-4411.

82. Cunha AB, Frey BN, Andreazza AC, Goi JD, Rosa AR, et al. (2006) Serum brain-derived neurotrophic factor is decreased in bipolar disorder during depressive and manic episodes. NeurosciLett 398: 215-219.

83. Kapczinski F, Frey BN, Andreazza AC, Kauer-Sant'Anna M, Cunha AB, et al (2008) Increased oxidative stress as a mechanism for decreased BDNF levels in acute manic episodes. Rev Bras Psiquiatr 30: 243-245.

84. Wu A, Ying Z, Gomez-Pinilla F (2004) The interplay between oxidative stress and brain-derived neurotrophic factor modulates the outcome of a saturated fat diet on synaptic plasticity and cognition. Eur J Neurosci 19: 1699-1707.

85. Kato T, Takahashi S, Shioiri T, Murashita J, Hamakawa H, et al. (1994) Reduction of brain phosphocreatine in bipolar II disorder detected by phosphorus-31 magnetic resonance spectroscopy. J Affect Disord 31:125-133.

86. Kato T, Shioiri T, Murashita J, Hamakawa H, Takahashi Y, et al. (1995) Lateralized abnormality of high energy phosphate metabolism in the frontal lobes of patients with bipolar disorder detected by phase-encoded 31P-MRS. Psychol Med 25: 557-566.

87. Deicken RF, Fein G, Weiner MW (1995) Abnormal frontal lobe phosphorus metabolism in bipolar disorder. Am J Psychiatry 152: 915-918.

88. Kato T, Stine OC, McMahon FJ, Crowe RR (1997) Increased levels of a mitochondrial DNA deletion in the brain of patients with bipolar disorder. Bio Psychiatry 42: 871-875.

89. Munakata K, Tanaka M, Mori K, Washizuka S, Yoneda M, et al. (2004) Mitochondrial DNA 3644T-->C mutation associated with bipolar disorder. Genomics 84: 1041-1050.

90. Konradi C, Eaton M, MacDonald ML, Walsh J, Benes FM, et al. (2004) Molecular evidence for mitochondrial dysfunction in bipolar disorder. Arch Gen Psychiatry 61: 300-308.

91. Sun X, Wang JF, Tseng M, Young LT (2006) Downregulation in components of the mitochondrial electron transport chain in the postmortem frontal cortex of subjects with bipolar disorder. J Psychiatry Neurosci 31:189-196.

92. Lenaz G (2001) The mitochondrial production of reactive oxygen species: Mechanisms and implications in human pathology. IUBMB Life 52: 159-164.

93. Wang JF (2007) Defects of mitochondrial electron transport chain in bipolar disorder: Implications for mood-stabilizing treatment. Can J Psychiatry 52: 753 762.

94. Billups B, Forsythe ID (2002) Presynaptic mitochondrial calcium sequestration influences transmission at mammalian central synapses. J Neurosci 22: 58405847.

95. Quiroz JA, Gray NA, Kato T, Manji HK (2008) Mitochondrially mediated plasticity in the pathophysiology and treatment of bipolar disorder Neuropsychopharmacology 33: 2551-2565. 